\title{
Gad67 haploinsufficiency reduces amyloid pathology and rescues olfactory memory deficits in a mouse model of Alzheimer's disease
}

Yue Wang ${ }^{1}$, Zheng Wu ${ }^{1 *}$ (D) Yu-Ting Bai ${ }^{1}$, Gang-Yi Wu ${ }^{1,2^{*}}$ and Gong Chen ${ }^{1 *}$

\begin{abstract}
Background: Alzheimer's disease (AD) is the most common age-related neurodegenerative disorder, affecting millions of people worldwide. Although dysfunction of multiple neurotransmitter systems including cholinergic, glutamatergic and GABAergic systems has been associated with AD progression the underlying mechanisms remain elusive. We and others have recently found that GABA content is elevated in AD brains and linked to cognitive deficits in AD mouse models. The glutamic acid decarboxylase 67 (GAD67) is the major enzyme converting glutamate into GABA and has been implied in a number of neurological disorders such as epilepsy and schizophrenia. However, whether Gad67 is involved in AD pathology has not been well studied. Here, we investigate the functional role of GAD67 in an AD mouse model with Gad67 haploinsufficiency that is caused by replacing one allele of Gad67 with green fluorescent protein (GFP) gene during generation of GAD67-GFP mice.

Methods: To genetically reduce GAD67 in AD mouse brains, we crossed the Gad67 haploinsufficient mice (GAD67-GFP ${ }^{+-}$) with 5xFAD mice (harboring 5 human familial AD mutations in APP and PS1 genes) to generate a new line of bigenic mice. Immunostaining, ELISA, electrophysiology and behavior test were applied to compare the difference between groups.
\end{abstract}

Results: We found that reduction of GAD67 resulted in a significant decrease of amyloid $\beta$ production in 5xFAD mice. Concurrently, the abnormal astrocytic GABA and tonic GABA currents, as well as the microglial reactivity were significantly reduced in the 5xFAD mice with Gad67 haploinsufficiency. Importantly, the olfactory memory deficit of 5xFAD mice was rescued by Gad67 haploinsufficiency.

Conclusions: Our results demonstrate that GAD67 plays an important role in AD pathology, suggesting that GAD67 may be a potential drug target for modulating the progress of AD.

Keywords: Alzheimer's disease, GAD67, Haploinsufficiency, Amyloid beta, Astrocytic GABA, Tonic inhibition, Neuroinflammation, Microglia, Olfactory memory

\footnotetext{
*Correspondence: neuronwu@gmail.com; gangyiwu1@gmail.com; gongchen@psu.edu

${ }^{1}$ Department of Biology, Huck Institutes of Life Sciences, Pennsylvania State

University, University park, PA 16802, USA

Full list of author information is available at the end of the article
} 


\section{Background}

Alzheimer's disease (AD) severely impacts the life quality of millions of people around the world. As the most common aging-related dementia, $\mathrm{AD}$ is characterized by accumulation of extracellular amyloid $\beta$ peptide $(A \beta)$ deposits and declining in cognition and memory [1]. Dysregulation of several neurotransmitter systems have been reported in the disease progress. GABAergic system is the principal inhibitory neurotransmitter system in the brain. Diverse lines of evidence suggest that GABAergic system is altered in AD brains, including GABA [2, 3], GABA synthetase, GABA receptors [4], GABA transporters [3] and GABAergic neurons [5, 6]. For example, the activity of GABAergic neurons in $\mathrm{AD}$ mice is significantly reduced [5], and even GABAergic neurons may be lost in AD brains [7, 8]. On the other hand, we and others have discovered that GABA may accumulate in the reactive astrocytes in both human and mouse AD brains [2, 4]. Therefore, GABA system may have a distinct role in $\mathrm{AD}$ pathology.

GABA is the major inhibitory neurotransmitter in the adult brain, and is converted from glutamate by glutamic acid decarboxylase (GAD). In mammalian brains, GAD contains two isoforms, GAD65 and GAD67 [9]. GAD65 is mainly localized at the presynaptic nerve terminals, while GAD67 is distributed throughout the cell. Importantly, over $90 \%$ of the basal GABA in the brain is synthesized by GAD67 [10, 11]. Accordingly, Gad67 knockout mice will die within a week after birth, but Gad67 haploinsufficient mice are viable although with abnormal behaviors [12]. In contrast, Gad65 knockout mice are largely normal, but exhibiting susceptibility to seizures [13]. Interestingly, dysfunction of GAD67 has been associated with several neurological disorders, including schizophrenia [14], bipolar disorders [15] and Parkinson's disease [16]. In fact, clinical trials targeting at GAD67 for the treatment of Parkinson's disease have achieved some success [17]. For AD, it is reported that GAD67 is not changed in brain tissues of postmortem $\mathrm{AD}$ patients, but whether Gad67 is involved in the progress of $\mathrm{AD}$ is largely unknown.

We investigated the functional role of GAD67 in AD by reducing Gad67 through crossing GAD67-GFP knock-in mice with $5 x$ FAD mice, which carry 5 human familial AD mutations in APP and PS1 genes [18]. Here, we found that the $A \beta$ plaques were significantly reduced by genetic downregulation of GAD67 in 5xFAD brains. Moreover, excessive microglia-mediated neuroinflammation, abnormal astrocytic GABA and excessive GABA tonic inhibition were also largely reduced in 5xFAD brains with Gad67 haploinsufficiency. Importantly, the olfactory memory deficit in the 5xFAD mice was rescued in the bigenic mice with Gad67 haploinsufficiency. Therefore, Gad67 haploinsufficiency in AD mouse model shows significant improvement in both
AD pathology and cognitive function. Our results suggest that GAD67 may potentially be a drug target for $\mathrm{AD}$ therapy.

\section{Methods}

Experimental animals

The GAD67-GFP knock-in mice in a C57BL/6 genetic background were obtained from (Tamamaki et al., 2003). A cDNA encoding Gfp was targeted to the Gad67 promoter locus and the resulting homozygous mice die prenatally but the heterozygous $\mathrm{GAD} 67^{+/-}$-GFP mice, in which one allele of Gad67 gene is replaced by Gfp, are viable and seem have no global morphological and overt behavioral deficits [19, 20] but see some social behavior changes [12]. The $5 x F A D$ transgenic mice also in a C57BL/6 genetic background, were purchased from the Jackson Lab (stock number: 006554), which harbored two mutations on human PS1 proteins (M146 L and L286 V) and three mutations on human APP [Swedish (K670 N/M671 L)], London (V717I) and Florida (I716V). This transgenic line was crossed with the C57BL/6 for breeding. To assess the effects of reduction of GAD67 in AD mouse model, we generated the compound mouse lines by crossing female GAD67+/-GFP mice with male $5 \times$ FAD mice, thus producing the following four genotypes: wild type (AD-GG-), GAD67-GFP ${ }^{+/-}$(AD$\mathrm{GG}+)$, 5xFAD (AD+GG-) and 5xFAD/GAD67-GFP ${ }^{+/-}(\mathrm{AD}$ $+\mathrm{GG}+$, bigenic mice) respectively. Of note, the $5 \mathrm{xFAD}$ mice in C57BL/6 J genetic background do not show very early onset. (2-3 month old) amyloid pathology and behavioral deficits as the original line generated by the Vassar group in a B6SJL background [Jackson Lab, https://www.jax.org/ strain/006554]; therefore, we assessed the effects of haploinsufficiency of Gad67 on amyloid pathology and behavioral deficits in 6-10 months old mice, when the $5 x F A D$ mice developed severe $A \beta$ burden and consistent behavioral deficits. The $5 \mathrm{xFAD}$ transgene is driven by a Thy- 1 promoter, which contains an estrogen responsive element, and is known to display a gender difference in $A \beta$ burden [21]; thus, we kept the female/male ratio comparable cross the 4 genotypes. For immunostaining age- and sex-matched littermates were used. For behavior test, several cohorts with similar age were pooled together for comparison.

The mice were housed in a 12/12-h light-dark cycle with food and water. All experimental procedures were approved by the Pennsylvania State University IACUC, in line with the guidelines of the National Institutes of Health for the Care and Use of Laboratory Animals.

\section{Immunohistochemistry and quantification}

Mice were deeply anesthetized by intraperitoneally injected with $2.5 \%$ Avertin $(10 \mathrm{ml} / \mathrm{kg})$, and then were perfused with ice-cold artificial cerebrospinal fluid (ACSF) to wash off blood in the brain, followed by $4 \%$ paraformaldehyde (PFA) fixation in phosphate-buffered 
saline (PBS). The brain was dissected out and further fixed overnight at $4{ }^{\circ} \mathrm{C}$ with $4 \%$ PFA. Brain tissue was sliced as sagittal sections at 45 um using the Leica vibratome and stored in $0.1 \mathrm{M} \mathrm{PB}$ at $4{ }^{\circ} \mathrm{C}$. For immunostaining, brain slices were rinsed with PBS for three times, $10 \mathrm{~min}$ each, and then treated with blocking solution (0.3\% Triton-X and $10 \%$ normal donkey and goat serum in $0.1 \mathrm{M} \mathrm{PBS}$ ) for $2 \mathrm{~h}$ at room temperature. The brain sections were next incubated with the following primary antibodies at $4{ }^{\circ} \mathrm{C}$ overnight [in 5\% normal donkey serum (NDS) and 5\% normal goat serum (NGS) in $0.1 \mathrm{M}$ PBS]: Monoclonal anti-GAD67 (mouse, 1:500, Millipore, MAB5406); polyclonal anti-GABA (rabbit, 1:1000, Sigma, A2052); Monoclonal anti-Parvalbumin (mouse, 1:2000, Sigma, P3088); Rabbit monoclonal antibeta Amyloid 1-42 (rabbit, 1:2000, Invitrogen, 700,254); Polyclonal anti-Glial Fibrillary Acidic Protein (chicken, 1:1000, Millipore, AB5541); polyclonal anti-Iba1 (rabbit, 1:500, Wako, 019-19,741); monoclonal anti-iNOS (mouse, 1:500, BD, 610,328). After washing three times with PBS, the brain sections were then incubated with appropriate secondary antibodies conjugated to Alexa Fluor 488 (1:1000, Jackson ImmunoResearch), Cy3(1:500, Jackson ImmunoResearch) or Alexa Fluor 647 (1:1000, Jackson ImmunoResearch) for $2 \mathrm{~h}$ at room temperature. After three times of washing using PBS, the brain sections were mounted on slides with the antifading mounting solution with DAPI (Invitrogen by Thermo Fisher Scientific, P36931).

For thioflavin-s staining, the brain slides were firstly treated following the immunohistochemistry protocol described above. After tissue samples were incubated in secondary antibody, the samples were firstly washed by diluted thioflavin-s in PBS $(2 \mu \mathrm{g} / \mathrm{ml})$ for $10 \mathrm{~min}$ on the shaker. Then wash the tissue sample with PBS for twice, 10 min each time. Samples were mounted using ProLong Gold antifade reagent (Life Technologies, P36934) on slides.

Fluorescent images were acquired with a Keyence microscope (BIOREVO BZ9000 viewer \& analyzer) or an Olympus confocal microscope (FV 1000). The confocal acquisition parameters were set at the same level for each of the individual protein immunostaining (see Additional file 1 Table S1). The mean intensity of each of the immunostaining marker was analyzed by the ImageJ software at the same setting (ImageJ 1.46r, Wayne Rasband, National Institutes of Health, USA).

\section{Human $A \beta$ Elisa}

Frontal cortex was isolated from $\mathrm{AD}+\mathrm{GG}$ - and $\mathrm{AD}+\mathrm{GG}+$ littermate mice, and were further lyzed with NP40 cell lysis buffer (Invitrogen, FNN0021) containing protease inhibitor cocktail (Sigma-Aldrich, P2714) and 1 mM PMSF protease inhibitor (Thermo Scientific, 36,978). The lyzed tissue samples were centrifuged at $13,000 \mathrm{rpm}$ at $4{ }^{\circ} \mathrm{C}$. The supernatant was collected for ELISA experiment. A $\beta 42$ and $A \beta 40$ measurement were conducted by using the human A 342 ELISA kit (Invitrogen, KHB3441) and human A $\beta 40$ ELISA kit (Invitrogen, KHB3481), and following the protocol of the ELISA kits strictly. Firstly, to bind antigen, load standards and samples to the corresponding wells in the $\mathrm{A} \beta$ antibody coated plates (included in the ELISA kit). Secondly, add the human $A \beta 42$ detector antibody (or human $A \beta 40$ detector antibody, respectively), tap the plate to mix thoroughly and then incubate for $3 \mathrm{~h}$ at room temperature on a shaker. Next, aspirate the solution and wash the wells with $1 \times$ wash buffer for 4 times. Add the HRP-conjugate antibody, incubate the plate at room temperature for $30 \mathrm{~min}$, and then washed the wells 4 times with $1 \times$ wash buffer. Then apply the stabilized chromogen in each well, incubate in the dark for $30 \mathrm{~min}$. After adding the stop solution in each well, read the plate within $30 \mathrm{~min}$ to get the absorbance at $450 \mathrm{~nm}$ and then generate the standard curve (SpectraMax Plus 384 Microplate Reader). With the value of optical density at $450 \mathrm{~nm}$ and the known concentration of the standard ladder, the $A \beta 42$ and $A \beta 40$ load of the unknown samples will be analyzed and quantified. Each sample is repeated twice and averaged.

\section{Brain slice electrophysiology}

The adult brain slice preparation followed previously described protocols [22]. Briefly, the 12-14 month old adult mice were transcardially perfused with cutting solution (in mM): $93 \mathrm{NMDG}, 93 \mathrm{HCl}, 2.5 \mathrm{KCl}, 1.25 \mathrm{NaH}_{2} \mathrm{PO}_{4}, 30$ $\mathrm{NaHCO}_{3}, 20$ HEPES, 15 Glucose, 12 N-Acetyl-L-cysteine, 5 Sodium ascorbate, 2 Thiourea, 3 Sodium pyruvate, 7 $\mathrm{MgSO}_{4}, 0.5 \mathrm{CaCl}$, pH 7.3-7.4, 300 mOsmo, bubbled with $95 \% \mathrm{O}_{2} / 5 \% \mathrm{CO}_{2}$. Then, the mouse brain was removed and cut at $300 \mu \mathrm{m}$ in the cutting solution at room temperature. Brain slices were collected in the cutting solution and incubated for $12-15 \mathrm{~min}$ at $32-34{ }^{\circ} \mathrm{C}$. The slices were kept in the holding solution with continuous $95 \% \mathrm{O}_{2} / 5 \% \mathrm{CO}_{2}$ bubbling (in mM): $92 \mathrm{NaCl}, 2.5 \mathrm{KCl}, 1.25 \mathrm{NaH}_{2} \mathrm{PO}_{4}, 30$ $\mathrm{NaHCO}_{3}, 20$ HEPES, 15 Glucose, $12 \mathrm{~N}$-Acetyl-L-cysteine, 5 Sodium ascorbate, 2 Thiourea, 3 Sodium pyruvate, 2 $\mathrm{MgSO}_{4}, 2 \mathrm{CaCl}_{2}$. After $0.5 \mathrm{~h}$ recovery in the holding solution, patch-clamp recording was performed in the standard aCSF (in mM): $124 \mathrm{NaCl}, 2.5 \mathrm{KCl}, 1.25 \mathrm{NaH}_{2} \mathrm{PO}_{4}, 26$ $\mathrm{NaHCO}_{3}, 10$ Glucose, $1.3 \mathrm{MgSO}_{4}, 2.5 \mathrm{CaCl}_{2}$.

To record the miniature IPSCs and the tonic GABA currents, $10 \mu \mathrm{M}$ DNQX, $50 \mu \mathrm{M}$ AP5 and $1 \mu \mathrm{M}$ TTX were added into the aCSF. The pipette was filled with high $\mathrm{Cl}^{-}$ internal solution $(\mathrm{mM}): 135 \mathrm{CsCl}, 5 \mathrm{Na}$-phosphocreatine, 10 HEPES, 5 EGTA, 4 MgATP, and 0.5 Na2GTP (pH 7.3 adjusted with $\mathrm{CsOH}, 280-290 \mathrm{mOsm}$ ). The tonic GABA current was revealed by the change of holding current after local perfusion of $100 \mu \mathrm{M}$ bicuculline (sigma). The mIPSCs were analyzed by Mini Analysis Program and assisted with 
visual check. Data were collected with a MultiClamp 700A amplifier and pCLAMP9 software (Molecular Devices).

\section{Olfactory behavior test}

Olfactory deficits of mice were tested using the odor habituation and cross dis-habituation test as described previously [23]. Briefly, four neutral odors [Ethyl valerate (\#290866), 2-Heptanone (\#537683), Isopentyl acetate (\#112674), (R)-(+)-Limonene (\#183164); Sigma Aldrich, St. Louis, MO] were diluted $1 \times 10^{-3}$ in mineral oil respectively. For each odor, a cotton applicator stick was firstly dipped in the odor solution and then enclosed inside a plastic tube to prevent a direct contact of liquid odor to the testing chamber. The four odors were randomly presented by inserting the odor stick into a port on the side of the mouse home cage, in 4 successive trials, $20 \mathrm{~s}$ each, and separated by $30 \mathrm{~s}$ inter-trial intervals. The mouse was caging individually in this odor test to prevent interference from social interaction with other mice. The olfactory behavior test was performed during the light phase of light-dark cycle $(12 \mathrm{~h} / 12 \mathrm{~h})$. An observer who was blinded to the genotypes of the animals during test and data analysis recorded the investigation time, which was defined as snout-oriented sniffing time within $1 \mathrm{~cm}$ of the odor presentation port [23]. For the measurement of investigation time, the duration time each mouse sniffs the odors presented in different trials were recorded. For investigation time (normalized) were measured by the investigation time (sec) in each trial of odor investigation divided by the sniffing time spent in the mouse's first trial in the same odor presentation. The investigation time and normalized investigation time were then analyzed using two-way ANOVAs followed by Bonferroni post-tests. The cross-habituation index was calculated by the average of subtracting the normalized fourth trial odor investigation value from the following normalized first trial odor investigation value. The crosshabituation index was further analyzed by one-way ANOVAs followed by LSD post hoc test, compare all pairs of columns.

\section{Data analysis}

Data were represented as mean \pm s.e.m. Student's t-test was used for statistical analysis in two-group comparison. One-way ANOVA or two-way ANOVA analysis was used for comparison among multiple groups. Statistical significance was set at $p<0.05$. In the olfactory behavior test, for the calculation of $\mathrm{F}$ and $P$ value of crosshabituation index, analysis the data using two - way ANOVA with LSD post hoc test via SPSS software. Statistical significance was set at $p<0.05$, labeled as ${ }^{*} \cdot p$ $<0.01$, labeled as $* * . p<0.001$, labeled as ${ }^{* * * *}$. All behavioral tests and analyses were performed blindly.

\section{Results}

GAD67 is reduced in GAD67-GFP knock-in mice

GAD67 is a major enzyme for producing GABA in the brain. Previous study has generated a GAD67-GFP transgenic mouse line [20], where GFP gene was knocked into the Gad67 gene locus so that GABAergic neurons will express GFP under the control of Gad67 promoter. However, the knock-in of GFP also destroyed the expression of GAD67. Therefore, the heterozygous GAD67-GFP mice had only one copy of Gad67, resulting in haploinsufficiency of Gad67. The homozygous GAD67-GFP mice were lethal, suggesting that GAD67 is critical for normal brain function. We first confirmed that the GAD67-GFP transgenic mice indeed had reduced GAD67 level. As expected, most of the GFPpositive cells $(>95 \%)$ were GABA-immunopositive neurons (Fig. 1a). Moreover, a subset of GFP-positive cells were also immunopositive for parvalbumin (PV), a typical marker for a subtype of GABAergic neurons (Fig. 1b). These data demonstrate that GFP is a reliable reporter for GABAergic neurons in the GAD67-GFP mice.

Because one allele of Gad67 is replaced by Gfp in the heterozygotes (haploinsufficiency), we next compared the expression level of GAD67 between GAD67-GFP ${ }^{+/-}$ and wildtype (WT) littermates. Consistent with previous finding that GAD67 was significantly reduced in the heterozygous GAD67-GFP ${ }^{+/}$mice [20], we also found that the immunoreactivity of GAD67 was reduced approximately by half in various brain regions in the heterozygotes (Fig. 1c). Thus, GAD67-GFP knock-in mice provide a unique transgenic mouse model for investigating the functional role of GAD67 in neurological disorders.

\section{Gad67 haploinsufficiency alleviates the amyloid $\beta$ burden in 5XFAD mouse brains}

To investigate the effect of genetic reduction of GAD67 on Alzheimer's disease (AD), we crossed the 5xFAD transgenic mice with GAD67-GFP ${ }^{+/-}$heterozygotes to generate four different genotypes of littermates: wild type (AD-GG-), GAD67-GFP ${ }^{+/-}$(AD-GG+), 5xFAD (AD +GG-) and 5xFAD/GAD67-GFP ${ }^{+/-}$(AD+GG+, bigenic mice). We first tested the effect of reducing GAD67 on the amyloid $\beta(A \beta)$ plaques, the hallmark for $A D$ [24]. Consistent with previous findings $[18,25]$, we found that 5xFAD mice (AD+GG-) developed severe A 342 deposits across many brain regions (Fig. 2a, top). However, the A $\beta 42$ level appeared to be reduced significantly in the bigenic mice (AD+GG+) with Gad67 haploinsufficiency (Fig. 2a, bottom) (age 10-11 months). For example, A 342 immunostaining signal accumulated at a high level in the frontal cortex (FCX) of $\mathrm{AD}+$ mice, and quantitative analysis revealed that both $A \beta 42$ intensity and 

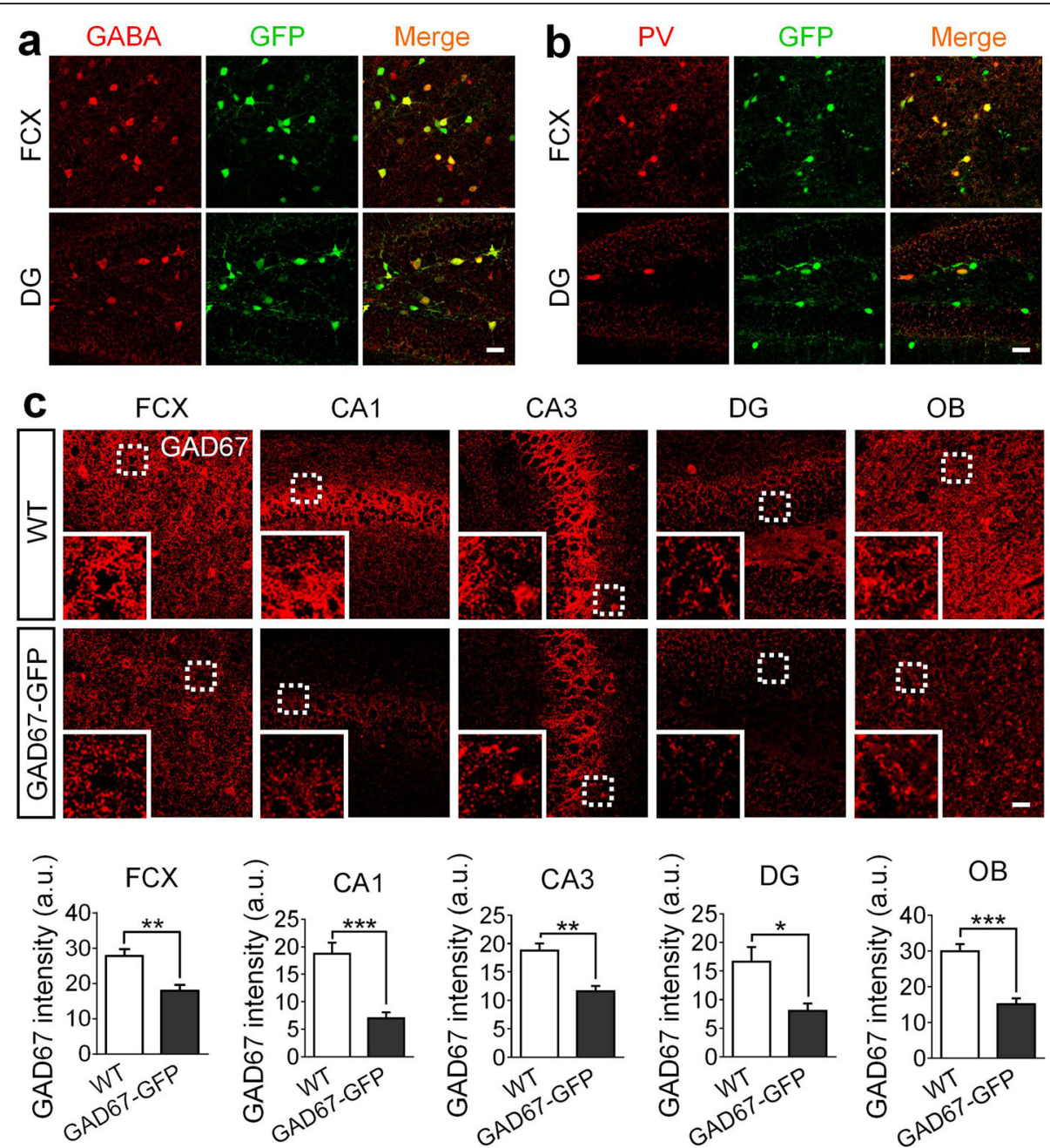

Fig. 1 Characterization of the GAD67-GFP knock-in transgenic mice. a Most GABA immunopositive cells (red) are also GFP positive (green) in both frontal cortex (FCX) and dentate gyrus (DG) in hippocampus of the adult GAD67-GFP knock-in mice. $\mathbf{b}$ In frontal cortex and dentate gyrus of hippocampus, all of the parvalbumin (PV) positive cells (one subtype of GABAergic neurons) (red) are labeled by GFP (green). c Representative confocal micrographs display the expression level of GAD67 (red) in GAD67-GFP knock-in mice and GFP-negative mice of 10-11 months old. Dotted line circled regions were zoomed in and were shown in the lower left corner of each micrograph. Quantification data showing GAD67 intensity in frontal cortex (FCX), CA1, CA3, dentate gyrus (DG) and olfactory bulb (OB) of GAD67-GFP knock-in mice is significantly reduced to about half of the GAD67 content level in WT controls. For a-c, scale bars represent $30 \mu \mathrm{m}$. $N=5 \mathrm{WT}$ mice and 5 GAD67-GFP knock-in mice. Data are presented as mean \pm s.e.m., ${ }^{*} p<0.05 ;{ }^{* *} p<0.01 ;{ }^{* * *} p<0.001$; Student's t-test

covered area were significantly decreased in $\mathrm{AD}+\mathrm{GG}+$ mice compared to the AD+GG- mice (Fig. $2 b$ and c). Besides immunostaining, we further employed an $A \beta$ ELISA kit (A $\beta 40$ and $A \beta 42)$ to examine the $A \beta$ production level in 5xFAD mouse brains with Gad67 haploinsufficiency. Consistent with our $A \beta 42$ immunostaining results, the ELISA test also showed a significant reduction of $A \beta 42$ (Fig. 2d; AD+GG-: $10.32 \pm 0.79, n=6$; AD+GG+: $7.31 \pm 0.55, \mathrm{n}=6, p<0.02$, Student's $t$ test), as well as A 340 (Fig. 2d; AD+GG-: $9.47 \pm 0.91, \mathrm{n}=6$; $\mathrm{AD}+\mathrm{GG}+$ : $5.95 \pm 0.80, \mathrm{n}=6, p<0.02$; Student's $t$ test) in the AD + GG+ FCX homogenates. Therefore, $A \beta$ production in the $5 x F A D$ mouse brains is downregulated by Gad67 haploinsufficiency.
We further analyzed the $A \beta 42$ level in the olfactory bulb (OB) and the piriform cortex (PIRC) in mice with different genetic background (Fig. 3). Consistently, the A 342 deposit was significantly increased in both $O B$ (Fig. 3a) and PIRC (Fig. 3c) in the AD+ mice compared to AD- mice (age 10-11 months). Interestingly, among $A D+$ mice, the GG+ mice showed a significant reduction of $\mathrm{A} \beta 42$ in the $\mathrm{OB}$ and PIRC compared to the GG- mice (Fig. 3a and c, bottom two rows). Quantitative analysis confirmed a significant decrease of $A \beta 42$ in both $O B$ and PIRC of bigenic mice (AD+GG+) compared to the 5xFAD littermates (AD+GG-) (Fig. 3b and d). We have also quantified the $A \beta 42$ level in the hippocampus, which showed slight reduction in $\mathrm{AD}+\mathrm{GG}+$ mice $(\mathrm{A} \beta 42: \mathrm{AG}+\mathrm{GG}-, 2.89 \pm 0.80$ vs 
a
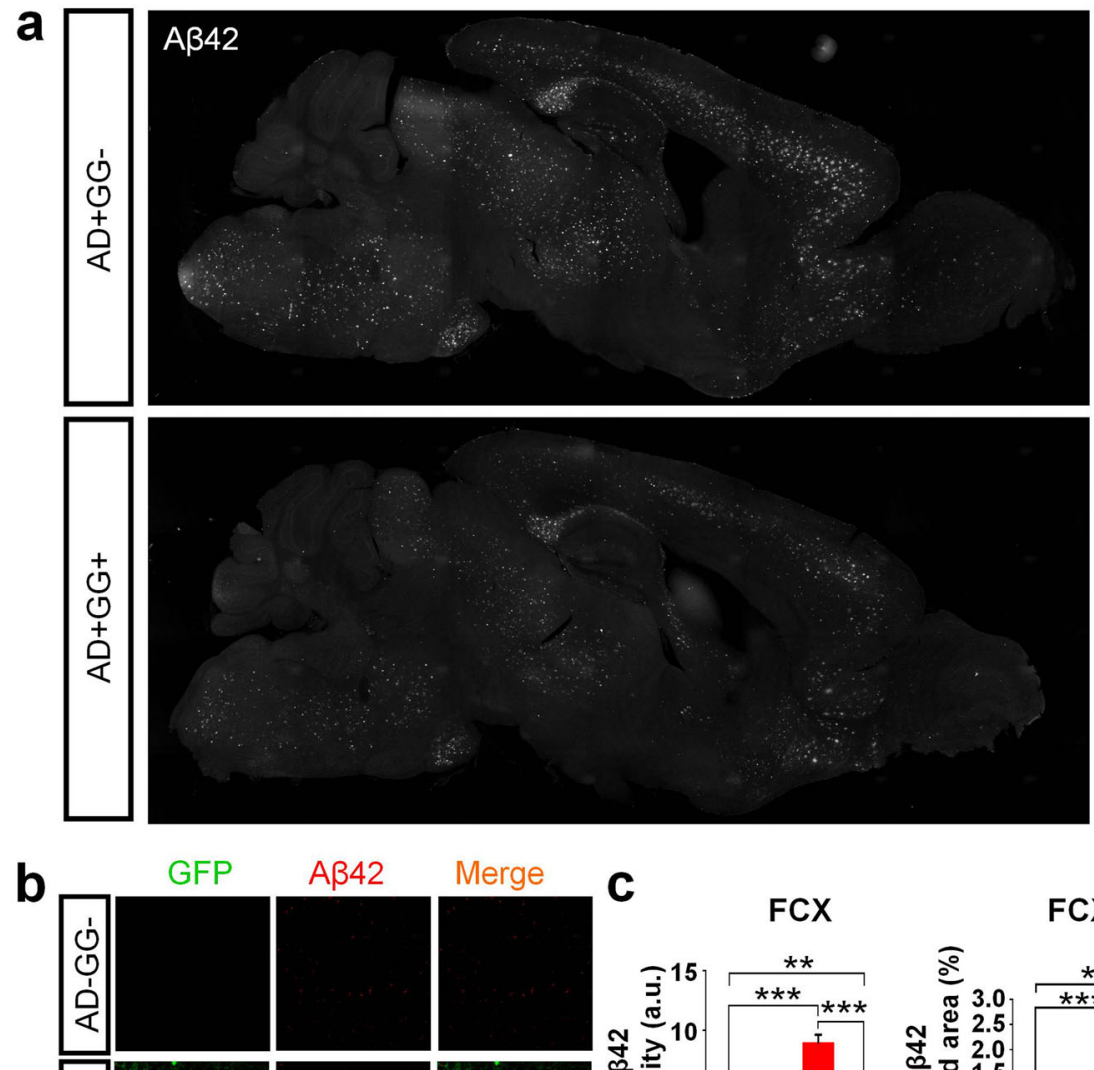

C
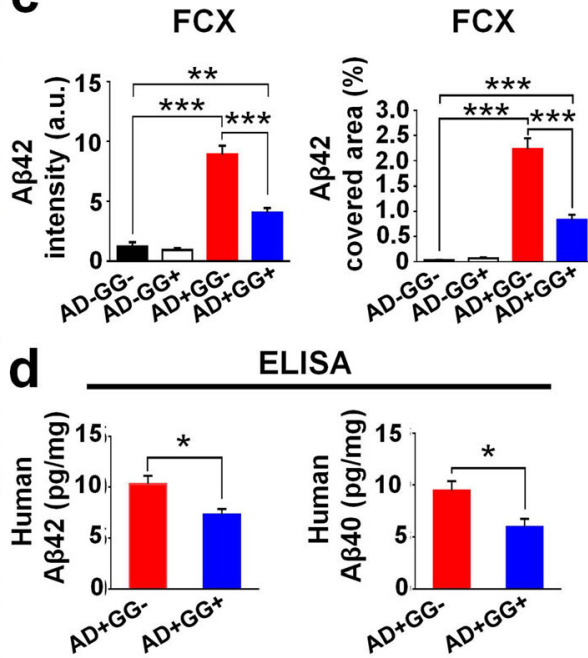

ELISA

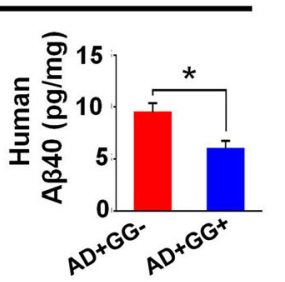

Fig. 2 A significant reduction of amyloid-beta plaques in the Gad67 haploinsufficiency 5xFAD mouse brains. a Images of the sagittal section of whole brain showing decreased $A \beta 42$ deposits (white) in AD+GG- (top) and AD+GG+ (bottom) mice of 10-11 months age. b Representative confocal images display the level of $A \beta 42$ deposits (red) in the four genotypes (AD-GG-, AD-GG+, AD+GG-, AD+GG+) generated by crossing of GAD67-GFP knock-in mice with 5xFAD mice. GFP cells showed in green. Scale bar $=30 \mu \mathrm{m}$. $\mathbf{c}$ Quantification analysis showing a remarkable reduction of $A \beta 42$ (left panel and right panel, $A \beta 42$ intensity and $A \beta 42$ covered area percentage, respectively) in the bigenic (AD+GG+) mice brain than 5xFAD mice of similar age. $N=6$ mice of 10-11 months age in each genotype groups (AD-GG-, AD-GG+, AD+GG-, AD+GG+). $\mathbf{d}$ Elisa data also showing the $A \beta 40$ and $A \beta 42$ were significantly reduced in 5xFAD mice by Gad67 haploinsufficiency (unpaired Student's $t$ test). Data are presented as mean \pm s.e.m., ${ }^{*} p<0.05 ;{ }^{* *} p<0.01 ;{ }^{* *} p<0.001$; one-way ANOVA with the Tukey's post-hoc test when comparing multiple groups

$\mathrm{AD}+\mathrm{GG}+, 1.18 \pm 0.13, n=3, p>0.1$; Student's $t$ test), but it's not as significant as in the cortical areas. We noted a significant low level of $A \beta 42$ in the hippocampus compared to that in the frontal cortex in $5 x F A D$ brains. One potential reason for such difference may be due to different GABAergic neuron population in the hippocampus versus the cortical regions, including the total number of
GABAergic neurons and the composition of various subtypes.

In addition to $A \beta 42$ immunostaining, we further employed thioflavin-s staining to verify our findings in the bigenic mice. Thioflavin-s is a chemical dye widely used to visualize $A \beta$ aggregates and hyperphosphorylated tau tangles [26]. We observed a significant reduction of 


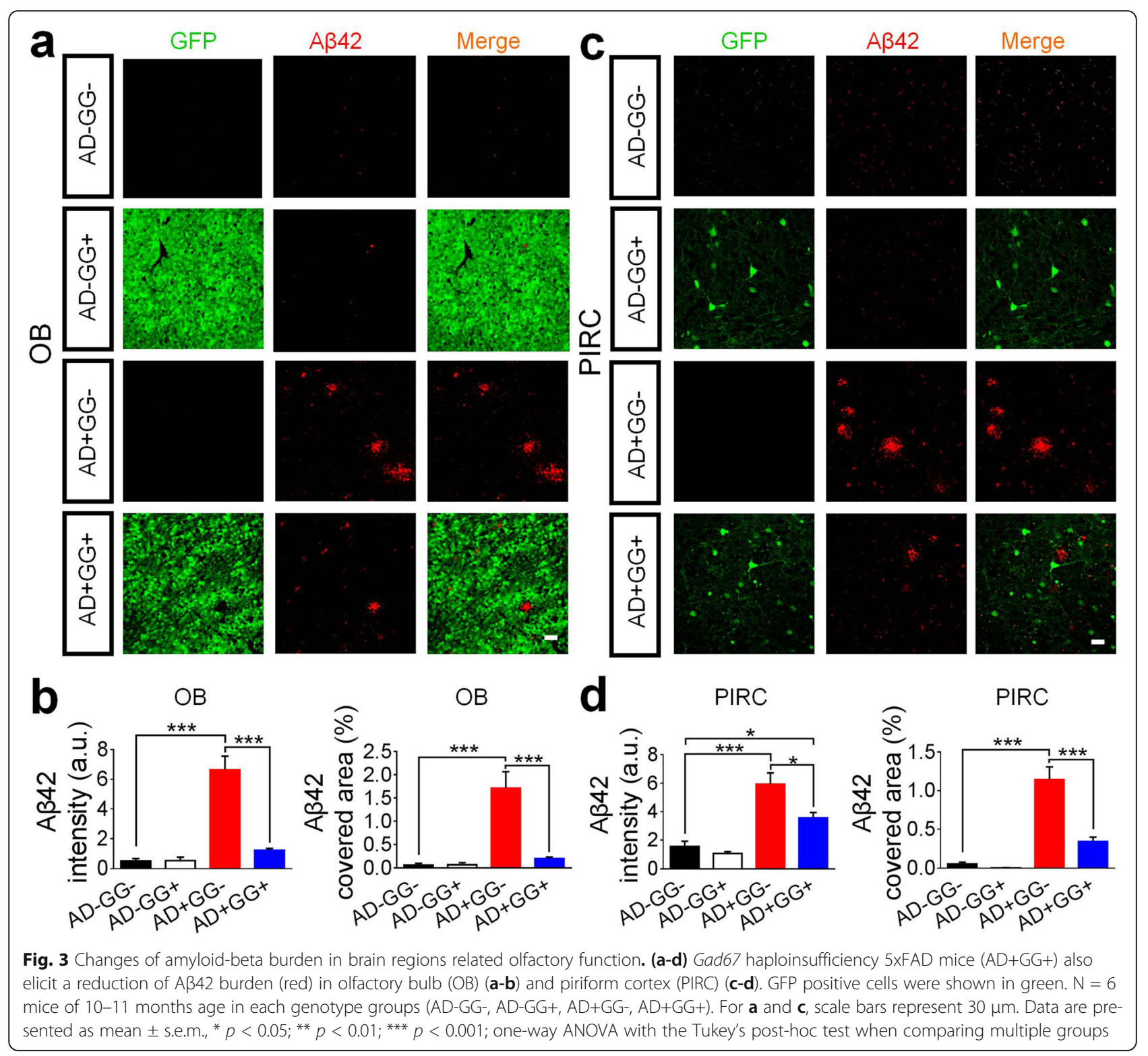

thioflavin-s labeled plaques in the FCX and PIRC of the bigenic mice $(\mathrm{AD}+\mathrm{GG}+)$ compared to the $\mathrm{AD}+\mathrm{GG}$ mice (Additional file 1: Figures S1). Accompanying the changes of $A \beta$ plaques, we also observed a significant reduction of neuronal density surrounding the $A \beta$ plaques in the FCX of 5 XFAD mice (10-11 months old), but such neuronal loss was partially rescued in bigenic mice $(\mathrm{AD}+\mathrm{GG}+)$ (Additional file 1: Figure $\mathrm{S} 2$ ), suggesting that Gad67 haploinsufficiency not only reduces amyloid plaques but also preserves surrounding neurons in the 5xFAD mouse model. Taken together, these data demonstrate an unexpected role of Gad67 haploinsufficiency in alleviating the $A \beta$ deposit and its detrimental effect on neurons in the 5xFAD mouse brains.

\section{Gad67 haploinsufficiency reduces astrocytic GABA in} 5xFAD mouse brains

Recently, we and others have found that GABA content is elevated in $A D$ mouse brains and in particular, an abnormal astrocytic GABA has been detected in both $\mathrm{AD}$ mouse model and postmortem human $\mathrm{AD}$ brain tissue $[2,3]$. Since GAD67 is a major enzyme for producing GABA in the brain, we examined whether the astrocytic GABA level in $\mathrm{AD}$ mice was altered by Gad67 haploinsufficiency. Brain sections of all four genotype littermate mice (AD-GG-, AD-GG+, $\mathrm{AD}+\mathrm{GG}-$, and $\mathrm{AD}+\mathrm{GG}+$; sex- and age-matched for each genotype) at 10-11 months old were double immunostained with GABA and astrocyte marker GFAP. Consistent with previous findings, we found a high 
level of GABA in the reactive astrocytes of the 5xFAD mice (AD+GG-), but not non-AD mice (AD-GG- and AD-GG+) (Fig. 4a). Interestingly, the abnormal astrocytic GABA was significantly reduced in the bigenic mice with Gad67 haploinsufficiency $(\mathrm{AD}+\mathrm{GG}+)$ compared to normal $5 \mathrm{xFAD}$ mice (AD+GG-) (Fig. 4a, bottom two rows). Quantitative analyses in the FCX, PIRC, and hippocampal CA1 regions all confirmed a uniform reduction of astrocytic GABA in a
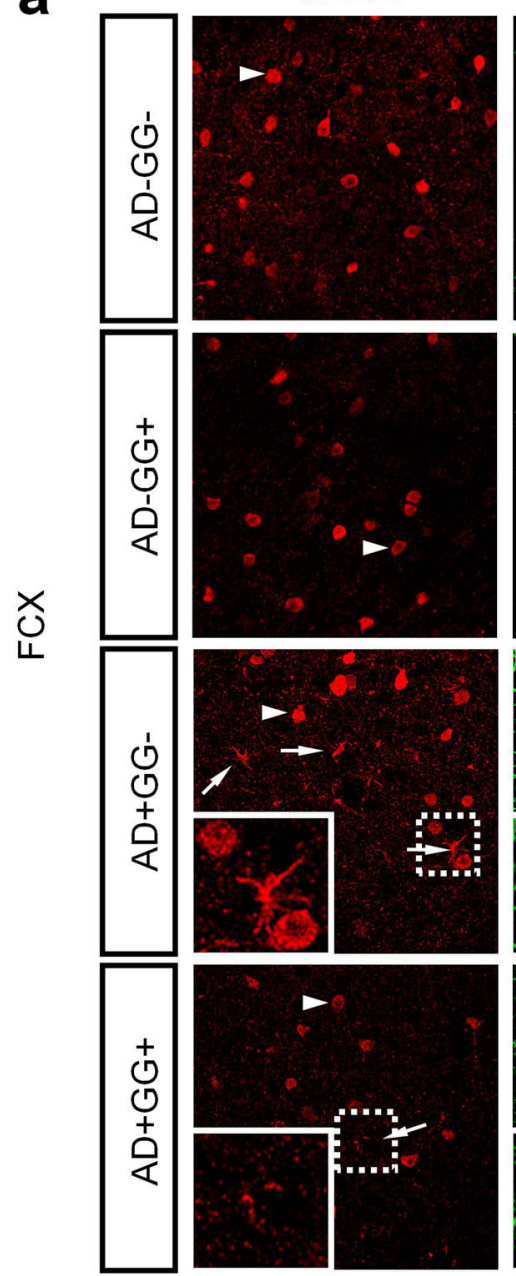

b

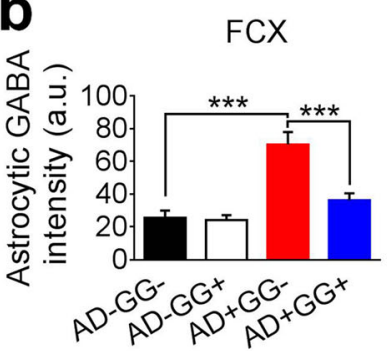

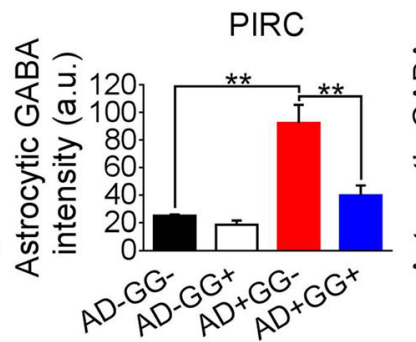

\section{GFAP}
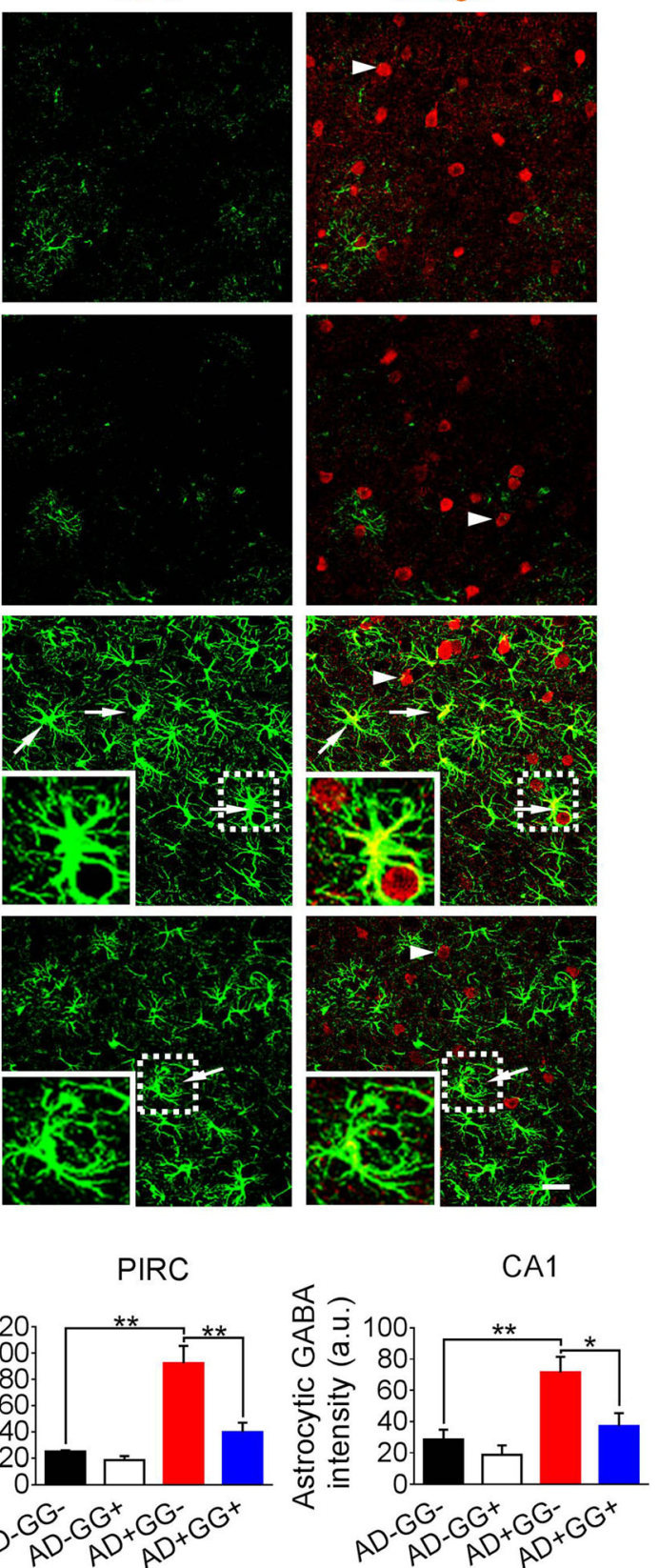

Fig. 4 Mitigation of the abnormal astrocytic GABA in 5xFAD mice with Gad67 haploinsufficiency. a The GABA content level (red) is abnormally enhanced in astrocytes (pseudo colored in green for merge purpose) in 5xFAD mice brain while it is under detectable level in AD-negative mice (the normal condition). Notably, the astrocytic GABA content level is significantly reduced in Gad67 haploinsufficiency 5xFAD brain. Arrowhead: GABA positive cells (red). Arrow: astrocytic GABA (red). Dotted line circled regions were zoomed in and were shown in the lower left corner of each micrograph. Scale bar represents $30 \mu \mathrm{m}$. b Quantification data showing the significant reduction of astrocytic GABA in frontal cortex (FCX), piriform cortex (PIRC) and CA1 region of the bigenic (AD+GG+) brain than the 5xFAD mice of similar age. $\mathrm{N}=6 \mathrm{mice}$ of $10-11$ months age in each genotype groups (AD-GG-, AD-GG+, AD+GG-, AD+GG+). Data are presented as mean \pm s.e.m., ${ }^{*} p<0.05$; ${ }^{* *} p<0.01$; ${ }^{* * *} p<0.001$; oneway ANOVA with the Tukey's post-hoc test when comparing multiple groups 
AD+GG+ mice (Fig. 4b). In contrast to the astrocytic GABA change, we observed no significant change of neuronal GABA level across all four groups of mice (Additional file 1: Figures S3), suggesting that neuronal GABA was not affected by Gad67 haploinsufficiency in the adult mice, consistent with previous study [20]. Together, our data suggest that the abnormal astrocytic GABA in $\mathrm{AD}$ mouse brains can be largely alleviated through genetic reduction of GAD67.

Gad67 haploinsufficiency decreases abnormal tonic GABA currents in 5xFAD mice

Previous studies reported that tonic inhibition is increased in $\mathrm{AD}$ mouse brains due to excessive GABA accumulation in the reactive astrocytes [2, 3], or in mouse brains after focal stroke [27]. Since we observed a significant reduction of astrocytic GABA in the $5 x F A D$ brains after genetic reduction of GAD67, we wondered whether tonic GABA currents might also be reduced correspondingly. Whole-cell patchclamp recordings were performed on the layer IV-VI cortical neurons (Fig. 5a and b). Consistent with our previous findings, tonic GABA currents were significantly increased in the 5xFAD mice (AD+GG-) compared to AD-GG- control littermates (Fig. 5e and f; AD-GG-, $14.4 \pm 2.3 \mathrm{pA}, n=9$ from 2 mice; AD+GG, $29.1 \pm 6.1 \mathrm{pA}, n=8$ from 2 mice; $p<0.02$; Oneway ANOVA). Interestingly, the abnormal tonic GABA currents in 5xFAD mouse brains were significantly reduced by Gad67 haploinsufficiency (Fig. 5e and f; $\mathrm{AD}+\mathrm{GG}+, 16.6 \pm 2.8 \mathrm{pA}, n=15$, from 2 mice, $p<0.03)$. On the other hand, there were no obvious differences in the miniature inhibitory postsynaptic currents (mIPSCs) among different groups (Fig. 5c and d). Thus, our results demonstrate that Gad67 haploinsufficiency results in a reduction of the abnormal GABA tonic currents in cortical neurons of 5xFAD mice.
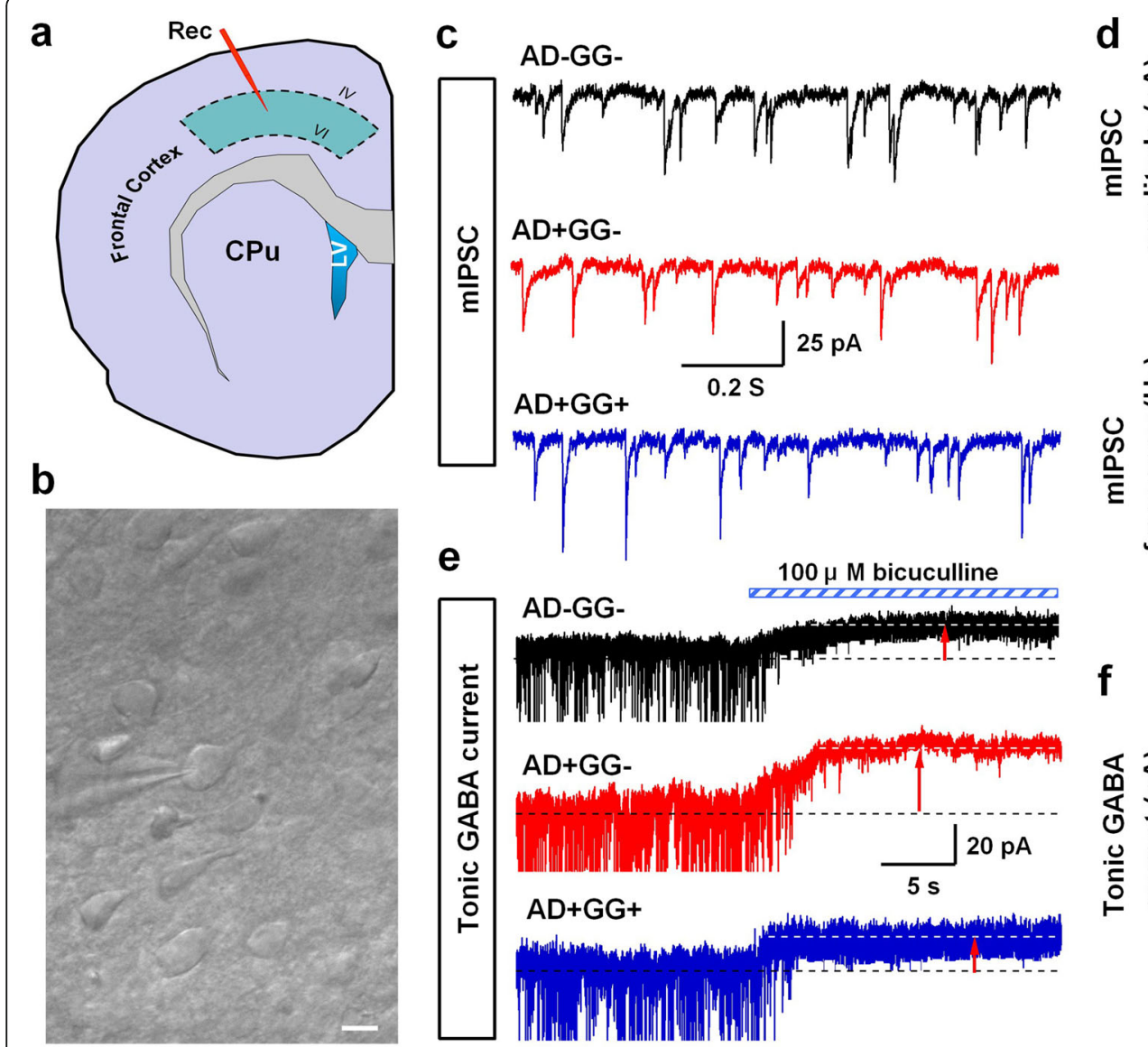

$A D+G G-$
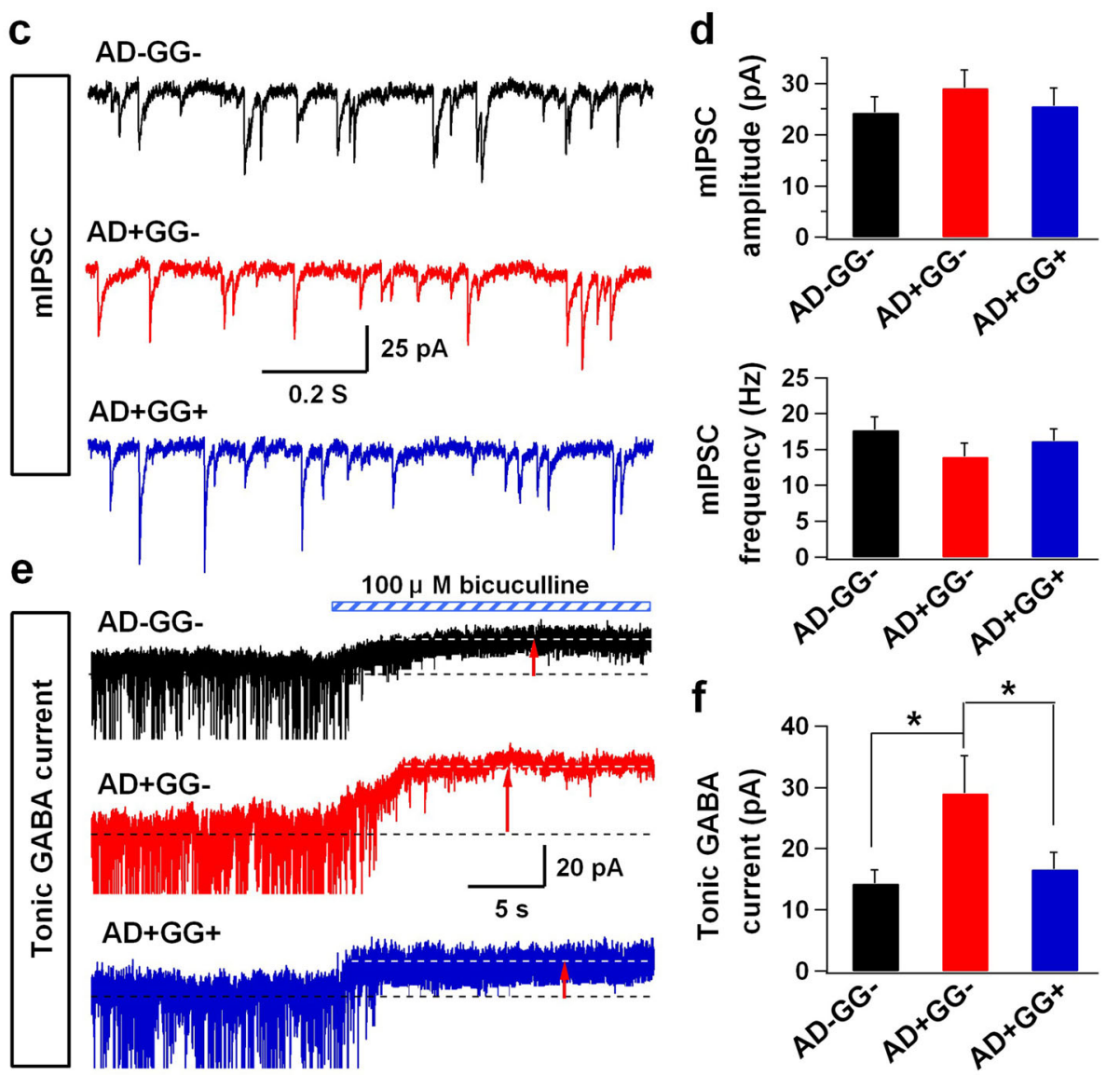

Fig. 5 Abnormal tonic inhibition is decreased in 5xFAD mice with Gad67 haploinsufficiency. a Schematic image illustrate the interesting cortical area for electrophysiology study. b A typical phase contrast image showing the whole cell recording in the adult brain slice. Scale bar $=10 \mu \mathrm{m}$. $\mathbf{c}$ Example of the mIPSCs traces in AD-GG-, AD+GG- and AD+GG+ groups. $\mathbf{d}$ Summary graph of mean amplitude and frequency of mIPSCs. e Representative trances of tonic GABA currents. $\mathbf{f}$ Quantification data showing the abnormal tonic GABA currents in 5xFAD mice are decreased by Gad67 haploinsufficiency. Data are presented as mean \pm s.e.m., ${ }^{*} p<0.05$; one-way ANOVA with the LSD post-hoc test 


\section{Microglia reactivity is ameliorated by Gad67 haploinsufficiency}

Previous study has suggested that microglia activity is regulated by GABA released from astrocytes [28]. Since the astrocytic GABA was dramatically decreased in 5xFAD mice with Gad67 haploinsufficiency (Fig. 4), we investigated whether microglia activity in 5xFAD mice might also be changed correspondingly. For this purpose, we investigated the inducible nitric oxide synthase (iNOS), a widely used marker for proinflammatory reactive microglia, in 5xFAD mice (Fig. 6a). In non-AD mice (AD-GG- and AD-GG+), iNOS was not detectable in microglia labeled by Iba1; but in $\mathrm{AD}+\mathrm{GG}$ - mice, strong iNOS immunoreactivity was detected (Fig. 6a). Surprisingly, in AD+GG+ mice, the iNOS immunoreactivity was significantly reduced compared to their $A D$ +GG- littermates (Fig. 6a). Quantitative analysis shows that in both the frontal cortex (Fig. 6b) and piriform cortex (Fig. 6c), the iNOS covered area was significantly reduced in $\mathrm{AD}+\mathrm{GG}+$ mice compared to that in $\mathrm{AD}+\mathrm{GG}$ - mice (Fig. 6b, FCX, AD+GG-: $1.40 \pm 0.28 \%, \mathrm{AD}+\mathrm{GG}+: 0.68 \pm 0.14 \%$, $p<0.02, n=6$; Fig. 6c, PIRC, AD+GG-: $1.02 \pm 0.28 \%$, AD $+\mathrm{GG}+: 0.27 \pm 0.07 \%, p<0.01, \mathrm{n}=6$ ). Consistent with the iNOS finding, the resting microglia $(\mathrm{Iba} 1+)$ displayed normal morphology with small soma and ramified processes, and evenly distributed in various brain regions in $\mathrm{AD}$ - mice (Fig. 6a). In contrast, in AD+GG- mouse brains, microglia was strongly activated, exhibiting hypertrophic soma with amoeboid-like morphology (Fig. 6a). Notably, in $\mathrm{AD}+\mathrm{GG}+$ mice, the microglia became less hypertrophic with more ramified processes compared to those found in $\mathrm{AD}$ +GG- mice, suggesting that the microglia reactivity in $5 x F A D$ mice was partially rescued by GAD67 haploinsufficiency (Fig. 6a, Iba1+, green). Together, these results suggest that genetic reduction of GAD67 partially ameliorates microglia reactivity in $5 x F A D$ brains.

\section{Gad67 haploinsufficiency rescues olfactory deficits in 5xFAD mice}

We found that several beneficial effects of Gad67 haploinsufficiency in 5xFAD mice were observed in various brain regions, including the key regions of olfactory circuits and limbic systems as described above. Olfaction sensory impairment has been reported both in $\mathrm{AD}$ patients and in mouse models $[29,30]$. Therefore, we further investigated whether Gad67 haploinsufficiency might rescue olfactory deficits in $5 x F A D$ mice. We performed the odor habituation and cross
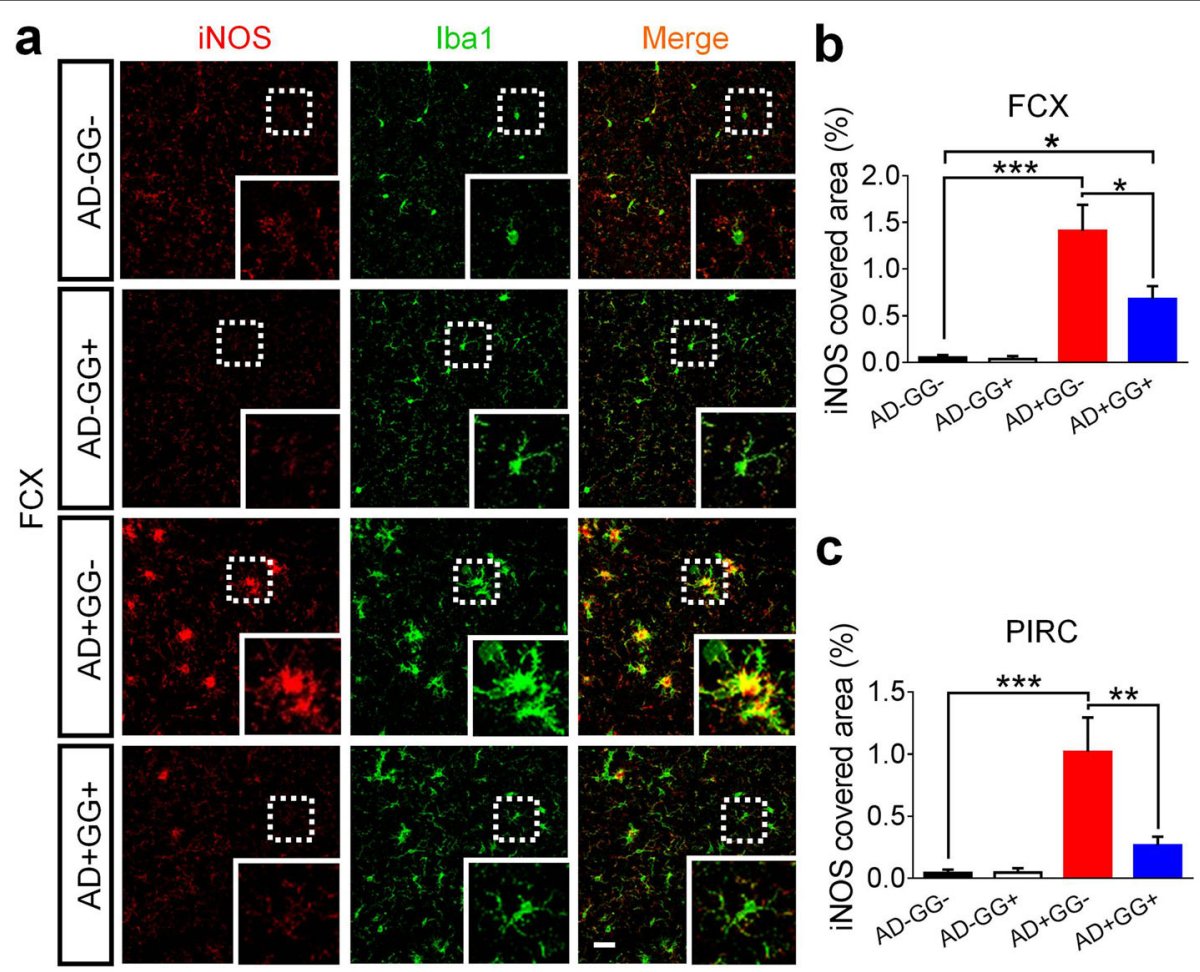

Fig. 6 Neuroinflammation mediated by microglia is alleviated in 5xFAD mice with Gad67 haploinsufficiency. a The iNOS positive immune cells (red), as the pro-inflammatory subtype of microglia (pseudo colored in green for merge purpose), is remarkably reduced in frontal cortex (FCX) and piriform cortex (PIRC) of bigenic brain (AD+GG+), close to the level in AD negative brain (normal condition). Dotted line circled regions were zoomed in and were shown in the lower right corner of each micrograph. Scale bar represents $30 \mu \mathrm{m}$. $\mathbf{b}$-c Quantification analysis displays a dramatic reduction of iNOS covered area percentage in both frontal cortex and piriform cortex of AD+GG+ than AD+GG- of similar age. $\mathrm{N}=6$ mice of 10-11 months age in each genotype groups (AD-GG-, AD-GG+, AD+GG-, AD+GG+). Data are presented as mean \pm s.e.m., ${ }^{*} p<0.05$; ** $p<0.01 ;{ }^{* * *} p<0.001$; one-way ANOVA with the Tukey's post-hoc test when comparing multiple groups 


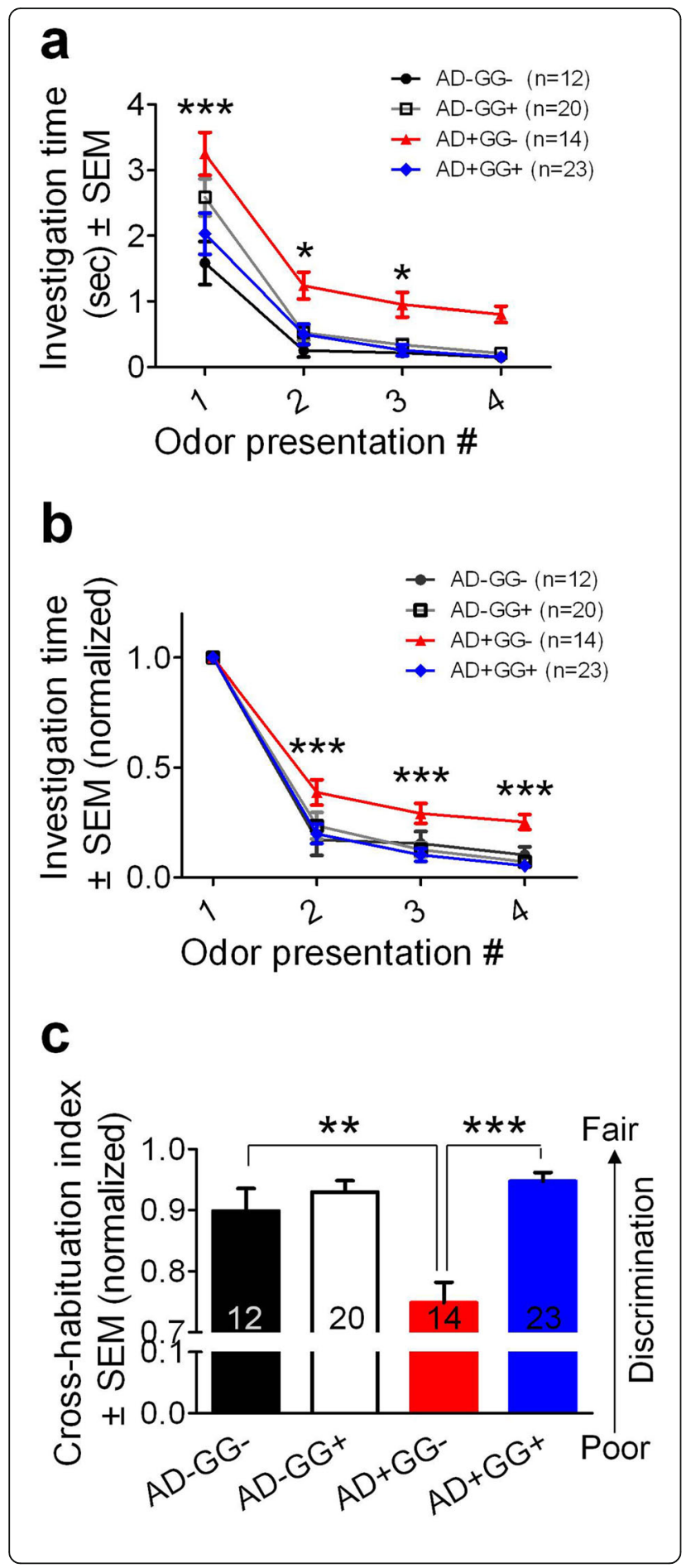

Fig. 7 Rescue of olfactory deficit in 5xFAD mice with Gad67 haploinsufficiency. Olfactory behavior test is applied to examine the extent of olfactory sensory impairment in the four genotypes of 68 months age (AD-GG-, AD-GG+, AD+GG-, AD+GG+). a Statistical graph showing the bigenic $(A D+G G+)$ mice displayed a reduction of investigation time in each odor presentation trials than 5XFAD mice (red line). $\mathbf{b}$ Quantification data showing the AD+GG+ mice displayed a reduction of investigation time (normalized) (blue line) than 5xFAD mice (red line). Notably, $\mathrm{AD}+\mathrm{GG}+$ mice displayed almost recovery of the impairment olfactory sensory function (which is a common pathological symptom in 5XFAD), according to the result that the statistic values are very close to that of AD-negative mice (black line: AD-GG-; grey line: AD$\mathrm{GG}+$ ). $\mathbf{c} A D+\mathrm{GG}+$ displayed a recovered cross-habituation index (mean \pm s.e.m., normalized). For (A)-(C), $n=12$ AD-GG-, 20 AD-GG+, $14 \mathrm{AD}+\mathrm{GG}-, 23 \mathrm{AD}+\mathrm{GG}+$ mice of $6-8$ months age. ${ }^{*} p<0.05$; ** $p<0.01$; ${ }^{* *} p<0.001$; two-way ANOVA followed by LSD post hoc test for comparison among multiple groups for multiple conditions

dis-habituation behavior tests as described in previous studies [23, 31]. Briefly, mice were exposed to four novel neutral odors presented in their home cages, and each odor was delivered across four successive trials. The investigation time for each of the 4 odors across four successive trials was recorded and quantified for olfactory habituation. Typically, when first exposed to an odor stimulus, mice would spend longest investigation time but quickly lost interest when exposed 2nd, 3rd, and 4th time to the same odor (Fig. 7a and $\mathrm{b}$, black line). The 5xFAD mice (AD+GG-) displayed consistent impairments in olfactory habituation, showing prolonged investigation time even after repeated exposure to the same stimulus (Fig. 7a and b, red line). Interestingly, the olfactory deficit of $\mathrm{AD}+\mathrm{GG}$ - was rescued in $5 \mathrm{xFAD}$ mice with Gad67 haploinsufficiency (AD+GG+) (Fig. 7a and 7b, blue line), consistent with the reduction of $A \beta$ in the olfactory bulb and piriform cortex of $\mathrm{AD}+\mathrm{GG}+$ mice. Similarly, AD+GG- mice exhibited a significant impairment in crosshabituation test, which was also rescued by Gad67 haploinsufficiency (Fig. 7c, AD-GG-: $0.90 \pm 0.04$; AD+GG+: $0.95 \pm 0.02, p>0.05, n=12$ AD-GG-, 20 AD-GG+, 14 AD +GG-, $23 \mathrm{AD}+\mathrm{GG}+$ ). Because we did not observe sex differences in olfactory behavioral tests (Additional file 1: Figures S4), data from both sexes were pooled and quantified together (Fig. 7). Two-way ANOVA analysis revealed that both genotypes and successive trials had a significant effect on the investigation time of olfactory habituation (genotype: $\mathrm{F}$ $(3260)=12.0 ; p<0.001$; successive trials: $\mathrm{F}(3260)=9.0$; $p<0.001)$. There was no interaction between genotypes and successive trials $(\mathrm{F}(9260)=0.27, p>0.05)$. Together, our results indicate that Gad67 haploinsufficiency rescues olfactory deficits in 5xFAD mice.

\section{Discussion}

In this study, we unexpectedly found that when 5xFAD mice were crossed with GAD-GFP mice that destroyed one allele of Gad67, the A $\beta$ load was significantly decreased throughout many brain regions. Further 
investigation revealed that accompanying such $A \beta$ reduction, the astrocytic GABA and tonic inhibition were significantly reduced, and microglial reactivity was also alleviated. More importantly, the olfactory memory deficit of AD mice was partially rescued by Gad67 haploinsufficiency. These results suggest that GAD67 plays an important role in modulating $A \beta$ production and may provide an important drug target for $\mathrm{AD}$ treatment.

\section{$A \beta$ reduction in 5xFAD mice with Gad67 haploinsufficiency}

As the principal inhibitory neurotransmitter in the brain, GABA plays a critical role in maintaining excitation/inhibition balance, which is important for information processing in the brain. Imbalance of excitation/inhibition has been implicated in a wide range of neurological and neuropsychiatric disorders including $\mathrm{AD}$ [32]. GABA is synthesized from excitatory neurotransmitter glutamate by two distinct but partial redundant glutamic acid decarboxylase isoforms, GAD65 and GAD67. Mice with genetic deletion of Gad65, which is mainly localized in the synaptic terminals, are viable and develop normally without obvious changes in the basal GABA transmission and brain GABA content, except an increase in seizure susceptibility $[13,33]$. In contrast, GAD67 is largely cytosolic and distributed evenly throughout the cells. Deletion of Gad67 leads to perinatal death and more than $90 \%$ reduction of GABA content [20, 34]. In addition to neuronal GABA function, several recent studies including our own have started to investigate non-neuronal changes of GABA system (review see [35, $36])$. In particular, we and others have shown that reactive astrocytes activated by $A \beta$ in $5 x F A D$ mice can accumulate a high amount of GABA, which can lead to exuberant tonic GABA inhibition and contribute to memory deficits [37]. Here, we demonstrate that genetic down-regulation of GAD67 dramatically reduces the reactive astrocytic GABA content, as well as $A \beta$ burden and inflammatory microglia in 5xFAD mice, further suggesting a strong link between astrocytic GABA and AD pathology.

There are now compelling evidences supporting that abnormal astrocytic GABA is associated with disease status such as brain injury and neurodegenerative disorders (for review, see [36]). However, the source(s) and mechanism(s) of astrocytic GABA release are still in debate. Previous reports have shown that human astrocytes have all of the machineries for GABA synthesis, metabolism and release, including GAD67, gamma-aminobutyric acid transaminase (GABAT), glia specific GABA transporter GAT3/4, and functional $\mathrm{GABA}_{\mathrm{A}}$ and $\mathrm{GABA}_{\mathrm{B}}$ receptors [28, 38]. We found that astrocytic GABA in Alzheimer's brain was synthesized by astrocytic GAD67 and released by astrocytespecific GABA transporter GAT3/4 [3]. At the same time, another study reported that glial GABA is synthesized through an unconventional pathway by monoamine oxidase B and released via bestrophin 1 (Best1) channel to mediate tonic inhibition [2]. Unfortunately, the clinic trial of MAO-B inhibitor for Alzheimer's treatment has failed in phase IIb clinical trial. Here, we provide in vivo genetic evidence showing that Gad67 haploinsufficiency can significantly alleviate the abnormal astrocytic GABA in a mouse model of $\mathrm{AD}$, underscoring a major role of GAD67-the conventional GABA biosynthesis pathway-in AD pathology.

While the precise mechanisms of GAD67 in AD require further study, one possible hypothesis based on our results is that genetic reduction of GAD67 reduces astrocytic GABA level in AD brains, corrects abnormal neuronal activity, and reduces $A \beta$ production. Consistent with our hypothesis, knockdown of GAD67 protein level has been reported to normalize neuronal activity in a rat model of Parkinson's disease [39]. In AD mouse models, the generation of $A \beta$ is found coupled with neuronal activity $[40,41]$, and $A \beta$ pathology can promote neuronal hyperexcitation [5]. Therefore, neuronal activity and $A \beta$ pathology may form a positive feedback loop to boost each other. Disrupt such loop may provide an alternative strategy to delay AD progression. For example, gamma oscillation is a normal rhythmic brain activity important for learning and memory, but it is disrupted in $\mathrm{AD}$ mouse brains. Recovery of this rhythmic gamma oscillation not only reduces the $\mathrm{A} \beta$ production but also rescues the memory deficits in an AD mouse model [5, 42]. Since $>90 \%$ GABA is synthesized by GAD67, and GABA is the major inhibitory neurotransmitter, it is possible that Gad67 haploinsufficiency will regulate GABA production both in neurons and astrocytes, which in turn will modulate neuronal activity during AD progression.

\section{Abnormal tonic GABA currents and AD}

Tonic GABA currents are mediated by extrasynaptic $\mathrm{GABA}_{\mathrm{A}}$ receptors with a high affinity for GABA and result in a persistent GABAergic inhibition, which is involved in several brain diseases including epilepsy, stroke and Alzheimer's disease [2, 3, 27, 43]. In AD brains, tonic inhibition is upregulated because of the activation of extrasynaptic $\mathrm{GABA}_{\mathrm{A}}$ receptors by astrocytic $\mathrm{GABA}$ release [2, 3], but synaptic $\mathrm{GABA}_{\mathrm{A}}$ receptor-mediated phasic inhibition is not changed significantly $[2,5]$. Here, we found that the abnormal GABA accumulation in the reactive astrocytes of 5xFAD mouse brains was remarkably reduced by Gad67 haploinsufficiency, and the abnormal tonic inhibition was also decreased correspondingly, consistent with the reduction of $A \beta$ production and amelioration of microglial reactivity in the $5 x F A D$ mice with Gad67 haploinsufficiency. Our finding of GAD67 in regulating $\mathrm{AD}$ pathology is also supported by earlier studies 
demonstrating a strong link between gamma oscillation activity $(20-80 \mathrm{~Hz})$ and $\mathrm{AD}[5,42]$ as well as tonic GABA inhibition [44, 45].

\section{Microglia reactivity and AD}

The characteristic ramified morphology of microglia and astrocytes and their close relationship with neurons put glial cells in a unique position to sense and maintain a homeostatic microenvironment in the brain (for review see [46]). In recent years, growing evidence has started to unravel an active role of microglia in neuroinflammation, a defense mechanism mediated primarily by reactive microglia and astrocytes [47-49]. However, direct interventions with neuroinflammation have failed in the clinical trials for $\mathrm{AD}$, underscoring the importance of further investigation of the molecular mechanisms of $\mathrm{AD}$ pathogenesis. Here, we made an important discovery that aberrant astrocytic GABA may be closely linked to microglia-mediated proinflammatory signaling iNOS and amyloidogenesis. Our findings open a new avenue for therapeutic intervention for AD. Interestingly, consistent with our finding of GAD67 in AD pathology, GABA has been reported to play a pro-neuroinflammatory role in a mouse model for multiple sclerosis [50]. Therefore, this newly discovered link among astrocytic GABA, microglial reactivity, and $A \beta$ production may offer new insight into the complex $\mathrm{AD}$ pathology. It is likely that a cocktail approach addressing multiple targets such as neurons, glial cells, and $A \beta$ together, rather than a single drug acting on a single target, will be future solutions to treat complicated syndromes such as AD.

\section{Conclusion}

In contrast to the traditional view that GABAergic transmission is relatively well-preserved in $A D$ patients, growing evidences have demonstrated more complex changes of the GABAergic system in $\mathrm{AD}$ pathology in recent years $[35,51]$. However, direct interventions with either GABA agonists or antagonists have failed in several human studies and clinical trials, raising the pressing needs for a further investigation of the underlying mechanisms and better intervention strategies. Here, by genetically targeting GAD67, an activityregulated major GABA synthesis enzyme, we show that Gad67 haploinsufficiency in AD mouse brains has significant beneficial effects on both pathological and behavioral outcomes. Although the precise mechanisms of how aberrant astrocytic GABA is linked to proinflammatory microglia and amyloidogenesis still requires further investigation, our study provides a new perspective for understanding the relationship between GABAergic functions and $\mathrm{AD}$ pathogenesis. Together with our previous finding of astrocytic GABA in AD brains, our results support the notion that GAD67 may be a potential target for developing a new treatment for $\mathrm{AD}$.

\section{Additional file}

Additional file 1: Table S1. Confocal imaging acquisition parameters. Figure S1. Reduction of $A \beta$ aggregates labeled by thioflavin-s in the frontal cortex (FCX) and piriform cortex (PIRC) of 5xFAD mice with GAD67 haploinsufficiency. Figure S2. Immunohistochemistry revealed less neuron loss in the frontal cortex region of 5xFAD mice with Gad67 haploinsufficiency. Figure S3. Neuronal GABA content level remains similar in the frontal cortex among different genotypes of mice. Figure S4 Similar performance between male and female mice of the same genotype in the olfactory behavioral test. (DOCX $1610 \mathrm{~kb})$

\begin{abstract}
Abbreviations
AD: Alzheimer's disease; A $\beta$ : $\beta$-Amyloid; FAD: Familiar Alzheimer's disease; FCX: Frontal cortex; GABA: Gamma-Aminobutyric acid; GAD: Glutamic acid decarboxylase; GFP: Green fluorescent protein; GG: GAD67-GFP ${ }^{+/}$;

iNOS: Inducible nitric oxide synthase; OB: Olfactory bulb; PIRC: Piriform cortex
\end{abstract}

\section{Acknowledgements}

We really appreciate Charles $\mathrm{H}$. Smith Endowment to support our research.

\section{Funding}

This work was supported by the National Institutes of Health R01 (AG045656, MH083911), Alzheimer's Association (ZEN-15-321,972) and Charles H. Smith Endowment Fund to G.C.

\section{Availability of data and materials}

All data generated in this study are available from the corresponding author on reasonable request.

\section{Authors' contributions}

YW played a major role in performing experiments and analyzing the data, as well as writing the initial draft of the manuscript. ZW initiated the study, generated most of the early results, performed the functional analysis, and revised the manuscript. YTB maintained the mouse lines and did genotyping. GYW and GC supervised the entire study, designed the experiments with $\mathrm{YW}$ and ZW, participated in data analysis and revised the manuscript. GC provides financial support for the study. All authors have read and approved the final version of the manuscript.

\section{Ethics approval}

All experimental procedures were approved by the Pennsylvania State University IACUC, in line with the guidelines of the National Institutes of Health for the Care and Use of Laboratory Animals (reference number: 46,803).

\section{Consent for publication}

Not applicable

\section{Competing interests}

The authors have no competing interests in the manuscript.

\section{Publisher's Note}

Springer Nature remains neutral with regard to jurisdictional claims in published maps and institutional affiliations.

\section{Author details}

${ }^{1}$ Department of Biology, Huck Institutes of Life Sciences, Pennsylvania State University, University park, PA 16802, USA. ${ }^{2}$ School of Life Science, South China Normal University, Guangzhou 510631, China. 
Received: 26 April 2017 Accepted: 21 September 2017

Published online: 10 October 2017

\section{References}

1. Tanzi RE, Bertram L. Twenty years of the Alzheimer's disease amyloid hypothesis: a genetic perspective. Cell. 2005;120:545-55.

2. Jo S, Yarishkin O, Hwang YJ, Chun YE, Park M, Woo DH, Bae JY, Kim T, Lee J, Chun $\mathrm{H}$, et al. GABA from reactive astrocytes impairs memory in mouse models of Alzheimer's disease. Nat Med. 2014;20:886-96.

3. Wu Z, Guo Z, Gearing M, Chen G. Tonic inhibition in dentate gyrus impairs long-term potentiation and memory in an Alzheimer's [corrected] disease model. Nat Commun. 2014;5:4159.

4. Limon A, Reyes-Ruiz JM, Miledi R. Loss of functional GABA (A) receptors in the Alzheimer diseased brain. Proc Natl Acad Sci U S A. 2012;109:10071-6.

5. Verret L, Mann EO, Hang GB, Barth AM, Cobos I, Ho K, Devidze N, Masliah E, Kreitzer AC, Mody I, et al. Inhibitory interneuron deficit links altered network activity and cognitive dysfunction in Alzheimer model. Cell. 2012;149:708-21.

6. Schmid LC, Mittag M, Poll S, Steffen J, Wagner J, Geis HR, Schwarz I, Schmidt B, Schwarz MK, Remy S, Fuhrmann M. Dysfunction of SomatostatinPositive Interneurons Associated with Memory Deficits in an Alzheimer's Disease Model. Neuron. 2016;92:114-25.

7. Andrews-Zwilling Y, Bien-Ly N, Xu Q, Li G, Bernardo A, Yoon SY, Zwilling D, Yan TX, Chen L, Huang Y. Apolipoprotein E4 causes age- and Taudependent impairment of GABAergic interneurons, leading to learning and memory deficits in mice. J Neurosci. 2010;30:13707-17.

8. Albuquerque MS, Mahar I, Davoli MA, Chabot JG, Mechawar N, Quirion R, Krantic S. Regional and sub-regional differences in hippocampal GABAergic neuronal vulnerability in the TgCRND8 mouse model of Alzheimer's disease. Front Aging Neurosci. 2015;7:30.

9. Erlander MG, Tillakaratne NJ, Feldblum S, Patel N, Tobin AJ. Two genes encode distinct glutamate decarboxylases. Neuron. 1991;7:91-100.

10. Lau CG, Murthy VN. Activity-dependent regulation of inhibition via GAD67. J Neurosci. 2012:32:8521-31.

11. Chattopadhyaya B, Di Cristo G, Wu CZ, Knott G, Kuhlman S, Fu Y, Palmiter RD, Huang ZJ. GAD67-mediated GABA synthesis and signaling regulate inhibitory synaptic innervation in the visual cortex. Neuron. 2007:54:889-903.

12. Sandhu KV, Lang D, Muller B, Nullmeier S, Yanagawa $Y$, Schwegler $H$, Stork O. Glutamic acid decarboxylase 67 haplodeficiency impairs social behavior in mice. Genes Brain Behav. 2014;13:439-50.

13. Kash SF, Johnson RS, Tecott LH, Noebels JL, Mayfield RD, Hanahan D, Baekkeskov S. Epilepsy in mice deficient in the 65-kDa isoform of glutamic acid decarboxylase. Proc Natl Acad Sci U S A. 1997;94:14060-5.

14. Kimoto S, Bazmi HH, Lewis DA. Lower expression of glutamic acid decarboxylase 67 in the prefrontal cortex in schizophrenia: contribution of altered regulation by Zif268. Am J Psychiat. 2014;171:969-78.

15. Benes FM, Lim B, Matzilevich D, Walsh JP, Subburaju S, Minns M. Regulation of the GABA cell phenotype in hippocampus of schizophrenics and bipolars. Proc Natl Acad Sci U S A. 2007;104:10164-9.

16. Lanoue AC, Dumitriu A, Myers RH, Soghomonian JJ. Decreased glutamic acid decarboxylase mRNA expression in prefrontal cortex in Parkinson's disease. Exp Neurol. 2010;226:207-17.

17. LeWitt PA, Rezai AR, Leehey MA, Ojemann SG, Flaherty AW, Eskandar EN, Kostyk SK, Thomas K, Sarkar A, Siddiqui MS, et al. AAV2-GAD gene therapy for advanced Parkinson's disease: a double-blind, sham-surgery controlled, randomised trial. Lancet Neurol. 2011;10:309-19.

18. Oakley H, Cole SL, Logan S, Maus E, Shao P, Craft J, Guillozet-Bongaarts A, Ohno M, Disterhoft J, Van Eldik L, et al. Intraneuronal beta-amyloid aggregates, neurodegeneration, and neuron loss in transgenic mice with five familial Alzheimer's disease mutations: potential factors in amyloid plaque formation. J Neurosci. 2006:26:10129-40.

19. Chen L, McKenna JT, Leonard MZ, Yanagawa Y, McCarley RW, Brown RE. GAD67-GFP knock-in mice have normal sleep-wake patterns and sleep homeostasis. Neuroreport. 2010;21:216-20.

20. Tamamaki N, Yanagawa Y, Tomioka R, Miyazaki J, Obata K, Kaneko T. Green fluorescent protein expression and colocalization with calretinin, parvalbumin, and somatostatin in the GAD67-GFP knock-in mouse. J Comp Neurol. 2003;467:60-79.
21. Sadleir KR, Eimer WA, Cole SL, Vassar R. Abeta reduction in BACE1 heterozygous null 5XFAD mice is associated with transgenic APP level. Mol Neurodegener. 2015;10:1

22. Ting JT, Daigle TL, Chen Q, Feng G. Acute brain slice methods for adult and aging animals: application of targeted patch clamp analysis and optogenetics. Methods Mol Biol. 2014;1183:221-42.

23. Wesson DW, Levy E, Nixon RA, Wilson DA. Olfactory dysfunction correlates with amyloid-beta burden in an Alzheimer's disease mouse model. J Neurosci. 2010;30:505-14.

24. Selkoe DJ. The therapeutics of Alzheimer's disease: where we stand and where we are heading. Ann Neurol. 2013;74:328-36.

25. Eimer WA, Vassar R. Neuron loss in the 5XFAD mouse model of Alzheimer's disease correlates with intraneuronal Abeta42 accumulation and Caspase-3 activation. Mol Neurodegener. 2013;8:2.

26. Zhang Z, Song M, Liu X, Kang SS, Kwon IS, Duong DM, Seyfried NT, Hu WT, Liu Z, Wang JZ, et al. Cleavage of tau by asparagine endopeptidase mediates the neurofibrillary pathology in Alzheimer's disease. Nat Med. 2014;20:1254-62.

27. Clarkson AN, Huang BS, Macisaac SE, Mody I, Carmichael ST. Reducing excessive GABA-mediated tonic inhibition promotes functional recovery after stroke. Nature. 2010:468:305-9.

28. Lee M, Schwab C, McGeer PL. Astrocytes are GABAergic cells that modulate microglial activity. Glia. 2011;59:152-65.

29. Stamps JJ, Bartoshuk LM, Heilman KM. A brief olfactory test for Alzheimer's disease. J Neurol Sci. 2013;333:19-24.

30. Doty RL, Kamath $\mathrm{V}$. The influences of age on olfaction: a review. Front Psychol. 2014:5:20

31. Cramer PE, Cirrito JR, Wesson DW, Lee CY, Karlo JC, Zinn AE, Casali BT, Restivo JL, Goebel WD, James MJ, et al. ApoE-directed therapeutics rapidly clear beta-amyloid and reverse deficits in $A D$ mouse models. Science. 2012;335:1503-6

32. Palop JJ, Mucke L. Amyloid-beta-induced neuronal dysfunction in Alzheimer's disease: from synapses toward neural networks. Nat Neurosci. 2010;13:812-8.

33. Asada H, Kawamura Y, Maruyama K, Kume H, Ding R, Ji FY, Kanbara N, Kuzume H, Sanbo M, Yagi T, Obata K. Mice lacking the $65 \mathrm{kDa}$ isoform of glutamic acid decarboxylase (GAD65) maintain normal levels of GAD67 and GABA in their brains but are susceptible to seizures. Biochem Biophys Res Commun. 1996;229:891-5.

34. Asada H, Kawamura $Y$, Maruyama K, Kume H, Ding RG, Kanbara N, Kuzume H, Sanbo M, Yagi T, Obata K. Cleft palate and decreased brain gamma-aminobutyric acid in mice lacking the $67-\mathrm{kDa}$ isoform of glutamic acid decarboxylase. Proc Natl Acad Sci U S A. 1997;94:6496-9.

35. Li Y, Sun $H$, Chen Z, Xu H, Bu G, Zheng H. Implications of GABAergic Neurotransmission in Alzheimer's Disease. Front Aging Neurosci. 2016:8:31.

36. Yoon BE, Lee CJ. GABA as a rising gliotransmitter. Front Neural Circuits. 2014:8:141.

37. Mitew S, Kirkcaldie MT, Dickson TC, Vickers JC. Altered synapses and gliotransmission in Alzheimer's disease and AD model mice. Neurobiol Aging. 2013;34:2341-51.

38. Lee M, McGeer EG, McGeer PL. Mechanisms of GABA release from human astrocytes. Glia. 2011;59:1600-11.

39. Horvath L, van Marion I, Tai K, Nielsen TT, Lundberg C. Knockdown of GAD67 protein levels normalizes neuronal activity in a rat model of Parkinson's disease. J Gene Med. 2011;13:188-97.

40. Bero AW, Yan P, Roh JH, Cirrito JR, Stewart FR, Raichle ME, Lee JM, Holtzman DM. Neuronal activity regulates the regional vulnerability to amyloid-beta deposition. Nat Neurosci. 2011;14:750-6.

41. Wu J, Petralia RS, Kurushima H, Patel H, Jung MY, Volk L, Chowdhury S, Shepherd JD, Dehoff M, Li Y, et al. Arc/Arg3.1 regulates an endosomal pathway essential for activity-dependent beta-amyloid generation. Cell. 2011:147:615-28.

42. laccarino HF, Singer AC, Martorell AJ, Rudenko A, Gao F, Gillingham TZ, Mathys $\mathrm{H}$, Seo J, Kritskiy O, Abdurrob F, et al. Gamma frequency entrainment attenuates amyloid load and modifies microglia. Nature. 2016:540:230-5.

43. Sun Y, Wu Z, Kong S, Jiang D, Pitre A, Wang Y, Chen G. Regulation of epileptiform activity by two distinct subtypes of extrasynaptic GABAA receptors. Mol Brain. 2013;6:21.

44. Mann EO, Mody I. Control of hippocampal gamma oscillation frequency by tonic inhibition and excitation of interneurons. Nat Neurosci. 2010;13:205-12. 
45. Ferando I, Mody I. In vitro gamma oscillations following partial and complete ablation of delta subunit-containing GABAA receptors from parvalbumin interneurons. Neuropharmacology. 2015;88:91-8.

46. Allaman I, Belanger M, Magistretti PJ. Astrocyte-neuron metabolic relationships: for better and for worse. Trends Neurosci. 2011;34:76-87.

47. Akiyama H, Barger S, Barnum S, Bradt B, Bauer J, Cole GM, Cooper NR, Eikelenboom P, Emmerling M, Fiebich BL, et al. Inflammation and Alzheimer's disease. Neurobiol Aging. 2000;21:383-421.

48. Glass CK, Saijo K, Winner B, Marchetto MC, Gage FH. Mechanisms underlying inflammation in neurodegeneration. Cell. 2010;140:918-34.

49. Heppner FL, Ransohoff RM, Becher B. Immune attack: the role of inflammation in Alzheimer disease. Nat Rev Neurosci. 2015;16:358-72.

50. Carmans S, Hendriks JJ, Slaets H, Thewissen K, Stinissen P, Rigo JM, Hellings N . Systemic treatment with the inhibitory neurotransmitter gamma-aminobutyric acid aggravates experimental autoimmune encephalomyelitis by affecting proinflammatory immune responses. J Neuroimmunol. 2013;255:45-53.

51. Limon A, Reyes-Ruiz JM, Miledi R. GABAergic drugs and Alzheimer's disease. Future Med Chem. 2011;3:149-53.

\section{Submit your next manuscript to BioMed Central and we will help you at every step:}

- We accept pre-submission inquiries

- Our selector tool helps you to find the most relevant journal

- We provide round the clock customer support

- Convenient online submission

- Thorough peer review

- Inclusion in PubMed and all major indexing services

- Maximum visibility for your research

Submit your manuscript at www.biomedcentral.com/submit 